\title{
Oestrogen increases the activity of oestrogen receptor negative breast cancer stem cells through paracrine EGFR and Notch signalling
}

\author{
Hannah Harrison ${ }^{1}$, Bruno M Simões ${ }^{2}$, Lynsey Rogerson ${ }^{1}$, Sacha J Howell ${ }^{3}$, Göran Landberg ${ }^{1,4}$ and Robert B Clarke ${ }^{2^{*}}$
}

\begin{abstract}
Introduction: Although oestrogen is essential for the development of the normal breast, adult mammary stem cells are known to be oestrogen receptor alpha (ER) negative and rely on paracrine signals in the mammary epithelium for mediation of developmental cues. However, little is known about how systemic oestrogen regulates breast cancer stem cell (CSC) activity.

Methods: Here, we tested the effects of oestrogen on CSC activity in vitro and in vivo and investigated which paracrine signalling pathways locally mediate oestrogen effects.

Results: CSC-enriched populations (ESA ${ }^{+} \mathrm{CD} 44^{+} \mathrm{CD} 24^{\text {low }}$ ) sorted from ER positive patient derived and established cell lines have low or absent ER expression. However, oestrogen stimulated CSC activity demonstrated by increased mammosphere and holoclone formation in vitro and tumour formation in vivo. This effect was abrogated by the anti-oestrogen tamoxifen or ER siRNA. These data suggest that the oestrogen response is mediated through paracrine signalling from non-CSCs to CSCs. We have, therefore, investigated both epidermal growth factor (EGF) and Notch receptor signals downstream of oestrogen. We demonstrate that gefitinib (epidermal growth factor receptor (EGFR) inhibitor) and gamma secretase inhibitors (Notch inhibitor) block oestrogen-induced CSC activity in vitro and in vivo but GSIs more efficiently reduce CSC frequency.
\end{abstract}

Conclusions: These data establish that EGF and Notch receptor signalling pathways operate downstream of oestrogen in the regulation of ER negative CSCS.

\section{Introduction}

Normal mammary stem cells (MSC) are responsible for the generation of adult mammary tissue and the distinct cell types within it as well as the extensive remodelling and enlargement of the gland during multiple cycles of pregnancy [1,2]. Mammary development is controlled by a variety of hormones, including oestrogen without which development cannot occur [3]. Isolation of MSC using cell sorting techniques has allowed extensive studies of this cell sub-population and it has been shown that these cells lack oestrogen receptor alpha (ER) $[4,5]$. In order to respond to systemic hormone signalling, these cells must, therefore, rely on local mediation of the signals by ER positive cells. There is good evidence

\footnotetext{
* Correspondence: rclarke@picr.man.ac.uk

${ }^{2}$ Breast Biology Group, Institute of Cancer Sciences, University of Manchester,

Paterson Institute for Cancer Research, Manchester, M20 4BX, UK

Full list of author information is available at the end of the article
}

that the epidermal growth factor receptor (EGFR) pathway, via binding of the amphiregulin ligand, is responsible for paracrine signalling that induces epithelial proliferation during ductal elongation of the mammary tree, but it is unknown whether this signal affects stem cells [6].

The development and progression of breast tumours has been proposed to be driven by breast cancer stem cells (CSC) identified by the cell surface phenotype ESA ${ }^{+} \mathrm{CD} 44^{+} \mathrm{CD} 24^{\text {low }}$ or aldehyde dehydrogenase (ALDH1) activity $[7,8]$. CSCs generate tumour heterogeneity and are able to reinitiate tumours in transplantation experiments [7]. CSCs are thought to be responsible for tumour recurrence as they have been shown to be inherently resistant to therapies, such as chemotherapy [9], radiotherapy [10] and endocrine treatment $[11,12]$.

There have been conflicting reports about the effects of oestrogen on breast CSCs with evidence reported 
that oestrogen can increase or decrease CSC number in breast cancer cell lines $[13,14]$. We predicted that these very different effects were due to the duration of hormone deprivation [12] compared to growth in standard conditions. In the current study, where oestrogen treatment is initiated after hormone withdrawal, oestrogen increases CSC activity and frequency measured both in vitro and in vivo. This is likely to be through paracrine regulation since breast CSCs are mainly ER negative. Here we establish that the EGF and Notch receptor signalling pathways are strong candidates as paracrine mediators of oestrogen effects on CSC activity.

\section{Materials and methods Patient samples}

Pleural effusion samples $(n=3$, see Additional file 1 , Table S1) were collected from patients with metastatic breast cancer during standard therapeutic drainage procedures, with fully informed consent (ethical approval was granted by the Central Office for Research Ethics Committee, study \#05/Q1403/159). Following collection of metastatic fluid, cells were pelleted by centrifugation at $800 \mathrm{~g}$. Pellets were resuspended in PBS and blood cells were removed by centrifugation of the cell suspension through 0.5 volumes of Lymphoprep solution (Axis Shield, Dundee, UK) at 600 g. Cells were cultured in DMEM:F12/20\% FCS/0.1\% nonessential amino acid solution/2.5 mM L-glutamine/PenStrep (Invitrogen, Paisley, UK).

\section{Cell lines}

Cell lines were purchased from the LGC Standards (Middlesex, UK); MCF7 (HTB-22), T47D (HTB-133), BT474 (HTB-20), MDA-MB-231 (HTB-26), authenticated by multiplex PCR assay using the AmpF/STR system (Life Technologies, Paisley, UK) and verified as mycoplasma free.

Monolayers of MCF7, T47D and BT474 were grown adherently in DMEM complete medium (DMEM/10\% foetal calf serum/2 mM L-glutamine/PenStrep) and MDA-MB-231 were cultured as monolayer in RPMI complete medium (RPMI/10\% FCS/1\% Sodium pyruvate/ $2 \mathrm{mM}$ L-glutamine/PenStrep). Cells were maintained in a humidified incubator at $37^{\circ} \mathrm{C}$ at an atmospheric pressure of $5 \%(\mathrm{v} / \mathrm{v})$ carbon dioxide/air. Cells were passaged at $80 \%$ confluence with a sub-cultivation ratio of $1: 4$. Cell lines were not cultured beyond 20 generations.

\section{Clonogenic culture}

Cells were plated at 50 cells $/ \mathrm{cm}^{2}$ in adherent conditions for 10 days (MCF7, T47D) or 6 days (MDA-MB-231). Colonies were fixed and stained with $1 \%$ crystal violet/ $70 \%$ ethanol and were classified by light microscopy. Colonies that had undergone five or more divisions, that is, containing 32 or more cells, were counted [15].

\section{Mammosphere culture}

A single cell suspension was prepared using enzymatic (0.125\% Trypsin-EDTA (Worthington Biochemical Corporation, Lakewood, NJ, USA)), and manual disaggregation (25 gauge needle). A total of 500 cells $/ \mathrm{cm}^{2}$ were plated in non-adherent conditions in mammosphere medium (DMEM-F12/B27/20 ng/ml EGF/PenStrep) for five days. Mammospheres (MS) greater than $50 \mu \mathrm{m}$ were counted.

\section{Flow cytometry}

Samples were resuspended at $\leq 1 \times 10^{6}$ in $100 \mu \mathrm{l}$ sorting buffer (1\% BSA/PBS) and incubated with $10 \mu \mathrm{l}$ of primary pre-conjugated antibody for 10 minutes at $4^{\circ} \mathrm{C}$. Following incubation the cells were washed with $1 \mathrm{ml}$ PBS and centrifuged at $800 \mathrm{~g}$ for two minutes. Antibodies include ESA-FITC (Dako, Cambridge, UK, BerEP4, F0860), CD44APC (BD Pharmingen, Oxford, UK, 559942) and CD24PE (Beckman Coulter, High Wycombe, UK, IMI1428U)

For analysis, cells were resuspended in $500 \mu \mathrm{l}$ of sorting buffer and passed through a $40 \mu \mathrm{m}$ sieve. Fluorescence was measured using the Becton Dickinson FACS Calibur and analysed using WinMDI 2.8 software (The Scripps Institute, La Jolla, CA, USA).

For sorting, cells were resuspended in $500 \mu \mathrm{l}$ of Hank's buffered saline solution (HBSS, Sigma, Cambridge, UK) and passed through a $40 \mu \mathrm{m}$ sieve. Cells were sorted, with HBSS as a sheath fluid, at 16 PSI using the Becton Dickinson FACS ARIA (Oxford, UK).

\section{Quantitative RT-PCR}

RNA was extracted using the RNAeasy kit (Qiagen, Manchester, UK) according to manufacturer's instructions and RNA was quantified using the Nanodrop spectrophotometer (Thermo Fisher Scientific, Basingstoke, UK). cDNA was produced using the Taqman reverse transcription kit (Life Technologies). qRT-PCR was performed using Sybrgreen (Bioline, London, UK) and was analysed on the 7900 PCR machine (Life Technologies) using custom PCR array plates (SA Biosciences, West Sussex, UK).

\section{Western blotting}

Protein was separated on an SDS-polyacrylamide gel and transferred to Hybond-C Extra nitrocellulose membrane (GE Healthcare, Buckinghamshire, UK). Primary antibodies included: SP1-ER (RM-9101-SO, Thermo Fisher Scientific, Basingstoke, UK), Cleaved N1-ICD (100-401407, Rockland, Gilbertsville, USA), Delta1 (Santa Cruz Biotechnology, Santa Cruz, CA, USA, sc-12530), Delta4 (Abcam, Cambridge, UK, ab7280), Jagged1 (Santa Cruz Biotechnology, sc-6011), Jagged2 (Santa Cruz Biotechnology, sc-08157), Actin (Santa Cruz Biotechnology, sc-1616), ERK (Abcam, ab2430) and ERK phospho-Y992 (Abcam, 
ab81440). Densitometry was performed using ImageJ software (NIH, Bethesda, USA) which is freely available [16]. Mean band intensity was measured and fold change from actin control was calculated.

\section{Oestrogen treatment}

Cells were plated in a monolayer at $1 \times 10^{4} / \mathrm{cm}^{2}$ in complete medium for 24 hours. At 24 hour intervals the medium was changed to low serum medium with decreasing concentrations of charcoal stripped serum, from $10 \%$ to $1 \%$. Charcoal stripped serum was prepared by mixing foetal calf serum with dextran coated charcoal and heating for 30 minutes at $55^{\circ} \mathrm{C}$. Serum was then centrifuged at $1,000 \mathrm{~g}$ for 15 minutes to remove charcoal. Finally the serum was passed through a $0.22 \mu \mathrm{m}$ sieve.

Cells were then cultured for 48 hours with 0 to $1 \mu \mathrm{M}$ $17 \beta$-estradiol to identify the best concentration. A total of $1 \mathrm{nM}$ was selected as the lowest concentration which gave significant changes (see Additional file 2, Figure S1) and was used with or without $1 \mu \mathrm{M} 4 \mathrm{OH}$-tamoxifen.

\section{SiRNA}

A SMARTpool of siRNA to ER (Thermo Scientific Dharmacon, ON-TARGET plus Human ESR1 (Fermentas GBMH, St Leon-Rot, Germany) was used to transfect cells using Lipofectamine 2000 (Invitrogen, Paisley, UK) according to the manufacturer's instructions in serum free medium. After six hours medium was changed to complete medium and cells were cultured as described above.

\section{Inhibition of paracrine signalling}

Inhibitors of Notch $(10 \mu \mathrm{M}$ DAPT $)$ and EGFR $(1 \mu \mathrm{M}$ gefitinib) signalling were added to oestrogen activated cell cultures ( $1 \mathrm{nM} 17 \beta$-estradiol) at Day 1 of treatment.

\section{In vivo limiting dilution}

Cells were treated as detailed above in CSS medium \pm $17 \beta$-estradiol \pm inhibitors for 48 hours. Cells were collected and resuspended at the desired dilution (10, 100 and 1,000 cells) in 50\% Matrigel (BD Biosciences, Oxford, UK)/MS medium before sub-cutaneous injection into NOD SCID IL2gammaR knock out (NSG) mice. Slow release oestrogen pellets were implanted sub-cutaneously into mice two days before cell injection $(0.72 \mathrm{mg}$, Innovative Research of America (Sarasota, USA). Mice were assessed for tumour presence twice weekly.

\section{Xenograft embedding and immunohistochemistry}

Tumours were formalin fixed and paraffin embedded. Antigen retrieval was performed at $98^{\circ} \mathrm{C}$ at $\mathrm{pH}$ 9. Slides were blocked with hydrogen peroxide and casein before incubation with the primary antibody (PanCytokeratin \#70622, DAKO, Cambridge, UK). Slides were then incubated with Envision secondary followed by DAB (DAKO).

\section{Statistical methods}

Throughout the paper data are represented as mean \pm SEM taken over a minimum of three independent experiments, unless otherwise stated. Statistical significance was measured using parametric testing, assuming equal variance, in the majority of experiments with standard t-tests for two-paired samples used to assess difference between test and control samples.

Analysis of variance was performed to assess changes in in vivo tumour growth rate. To calculate CSC frequency, the L-Calc software (The Walter and Eliza Hall Institute of Medical Research, Parkville, USA) was used which is freely available [17].

\section{Results}

Oestrogen stimulation increases the breast cancer stem cell-like population

The effect of $17 \beta$-estradiol on the CSC proportion was assessed in three ER positive patient derived cell samples, three ER positive cell lines (MCF7, T47D and BT474) and an ER negative cell line (MDA-MB-231). Following oestrogen deprivation for six days and then 48 hours culture in 1 nM $17 \beta$-estradiol, the mammosphere forming cell (MFC) number was significantly increased in all ER positive but not ER negative primary cells and cell lines (Figure 1A). Holoclone forming cell (HFC) number also significantly increased in the ER positive but not ER negative cell lines (Figure 1B). ER positive cells also contained a significantly higher number of $\mathrm{ESA}^{+} \mathrm{CD} 44^{+} \mathrm{CD} 24^{\text {low }}$ cells following the 48 hour exposure to $17 \beta$-estradiol compared to control conditions (Figure 1C).

To verify that this effect was due to activation of oestrogen signalling we first knocked down ER gene expression using siRNA (Figure 2A). In cells cultured in the presence of ER siRNA and $17 \beta$-estradiol, no significant increase in MFC is seen, establishing ER as the major player in the oestrogenic response (Figure $2 \mathrm{~B}$ ).

Next, to block ER signalling in primary cells and other cell lines, cells were cultured in the presence of oestrogen and the anti-oestrogen tamoxifen. This treatment efficiently blocked $17 \beta$-estradiol effects on ER positive patient derived cells and cell lines (Figure 2C) although primary 2 remained raised compared to control cells. HFC was also reduced in cell lines (Figure 2D) but no changes in MFC or HFC number were seen in ER negative cells.

\section{Breast cancer stem cells have low expression of ER}

In order to demonstrate whether the effects of oestrogen and tamoxifen were direct, ER positive patient derived cells (primary 2) and MCF7 cells were FACS sorted to assess the oestrogen receptor status of the CSC enriched $\mathrm{ESA}^{+} \mathrm{CD} 44^{+} \mathrm{CD} 24^{\text {low }}$ sub-population (Additional file 3, Figure S2 and Additional file 4, Figure S3 show gating procedure and example. For more details see [18]). Cells 
A

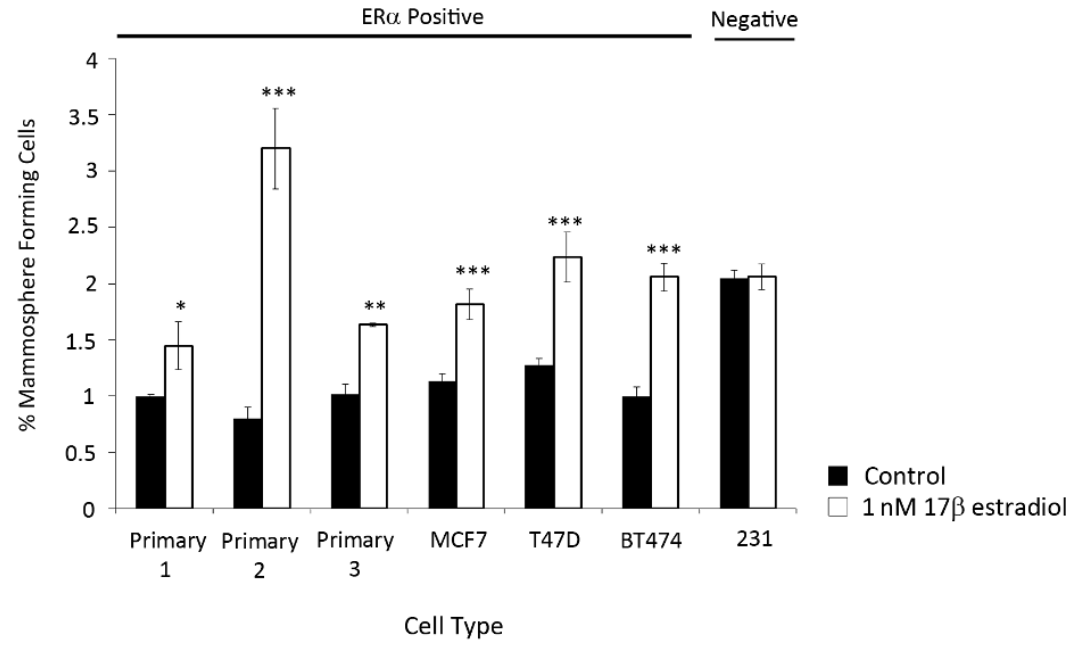

B

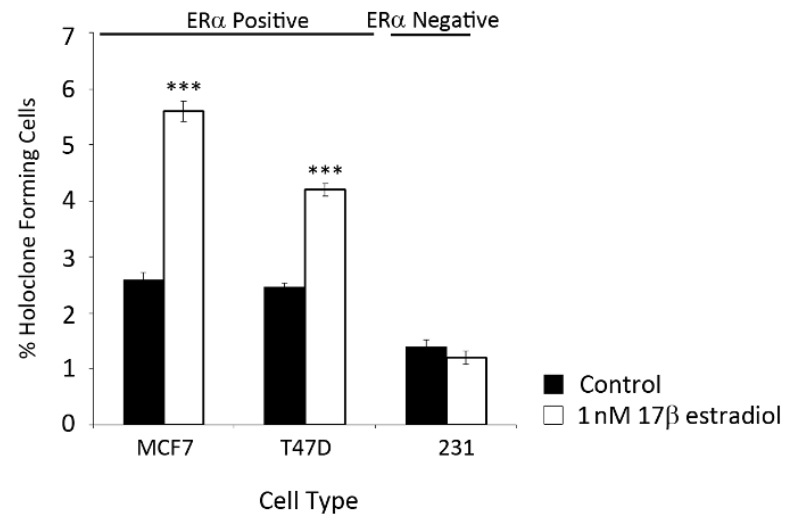

C

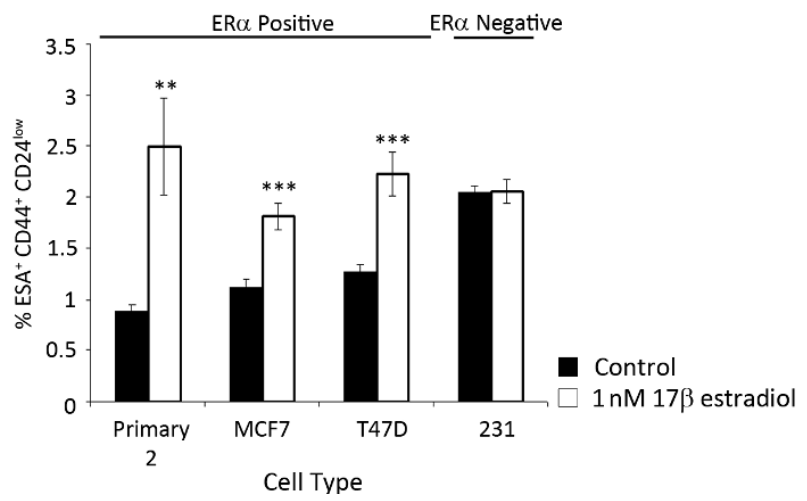

Figure 1 Oestrogenic effects on cancer stem cells. Cells were cultured for 48 hours in a monolayer in the presence of $1 \mathrm{nM} 17 \beta$-estradiol or vehicle control and CSC assays were performed in ER positive cells (primary, MCF7, T47D and BT474) and ER negative cells (231). (A) Mammosphere formation, (B) holoclone formation and (C) expression of ESA ${ }^{+}$CD $44^{+}$CD24 ${ }^{\text {low }}$ were measured. Means plotted \pm SEM, ${ }^{*} P<0.05$, ${ }^{* *} P<0.01$, ***P $P<0.001$.

were then lysed and ER expression was assessed by Western blot. In both cases, CSC-enriched cells (Population $\left.1, \mathrm{ESA}^{+} 44^{+} 24^{\text {low }}\right)$ had very low or absent receptor expression compared to more differentiated tumour cells (Figure 3A, B). Populations 2 to 4 (differentiated tumour cells) expressed between 1.7- and 8-fold more ER in the 


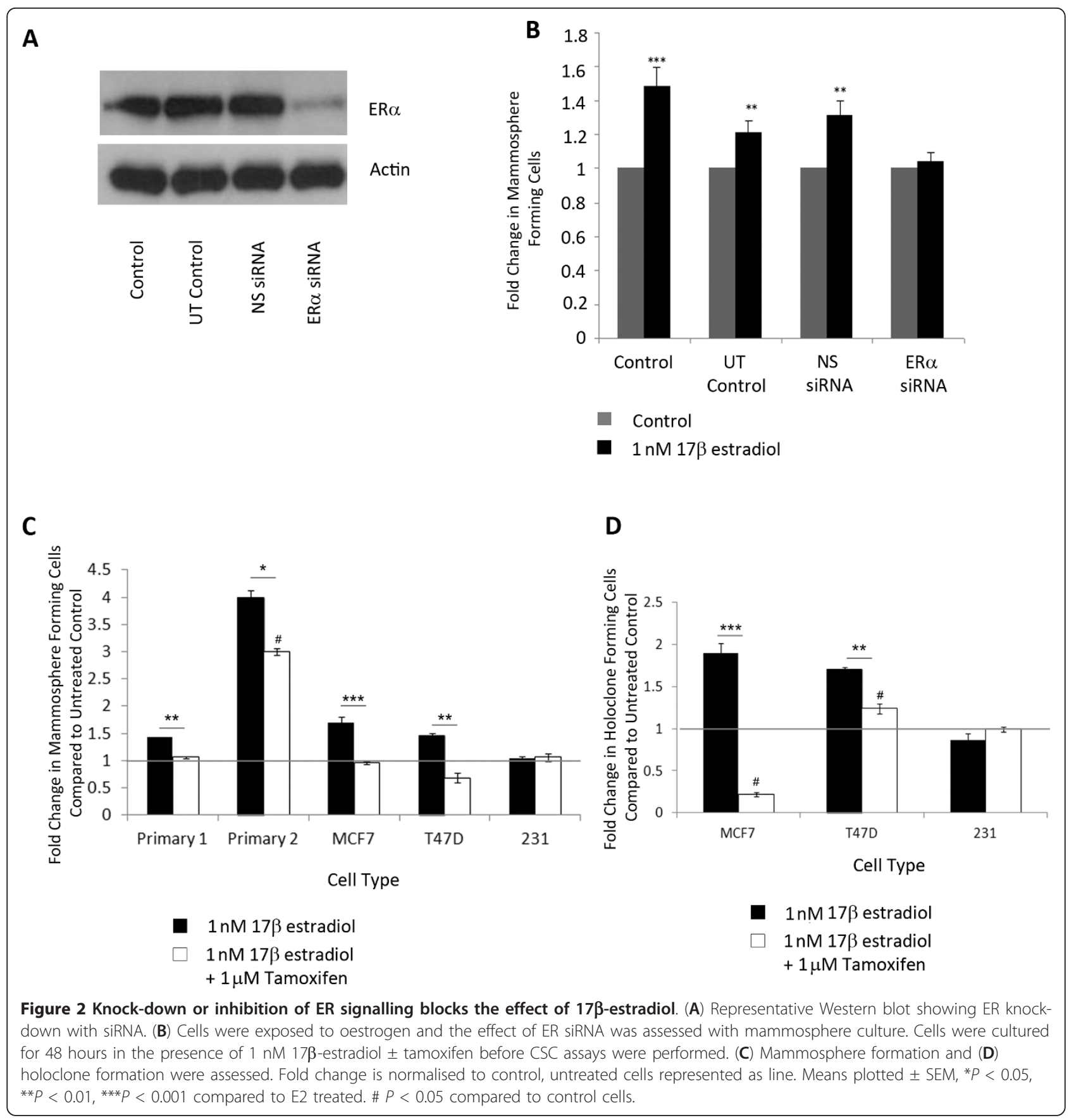

primary cells and between 1.5 - and 3.5-fold more ER in MCF7 cells $(P<0.05)$.

Collection of anoikis resistant (AR) cells is another method previously reported to enrich for the CSC population $[18,19]$. Primary cells taken from an ER positive patient derived sample (primary 3) and ER positive cell lines were plated in non-adherent culture for 16 hours before protein and RNA were prepared from the total and AR populations. In all cases the AR population showed low/no expression of ER assessed by Western blot (Figure 3C) and
qRT-PCR and several fold lower levels of expression of known oestrogen responsive genes compared to total cell populations (Figure 3D). These findings indicate that paracrine signals from the ER positive cells are required to initiate increases in breast CSC number.

\section{EGFR signalling plays a role in the oestrogenic effect on} breast cancer stem cells

In the normal breast, evidence suggests that the paracrine oestrogen signal occurs via amphiregulin (AREG) 
A
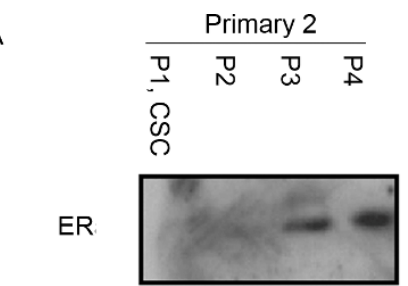

Actin

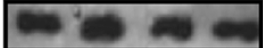

B

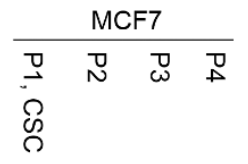

ER

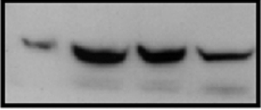

Actin

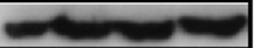

C

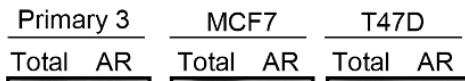

ER

Actin
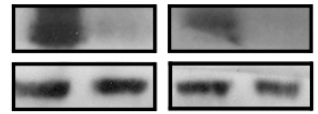

D
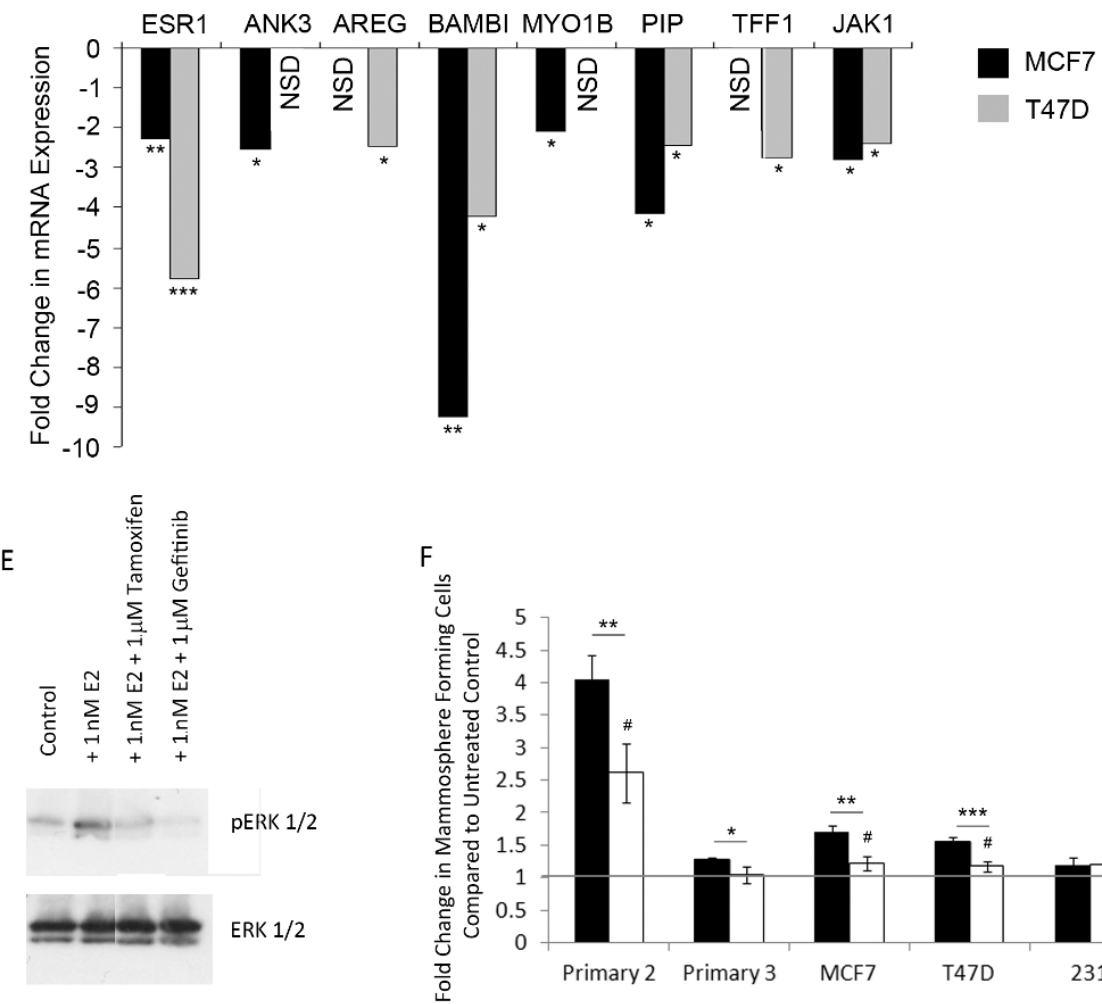

$\left.\begin{array}{l}5 \\ 5 \\ 4 \\ 5 \\ 3 \\ 5 \\ 2 \\ 5 \\ 5 \\ 1 \\ 5 \\ 0\end{array}\right]$

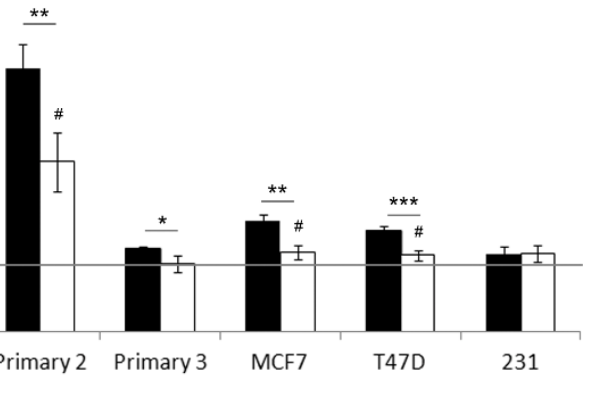

Cell Type

- $1 \mathrm{nM} 17 \beta$ estradiol

$1 \mathrm{nM} 17 \beta$ estradiol

$+1 \mu \mathrm{M}$ Gefitinib

Figure 3 Breast cancer stem cells have low expression of ER. Cells were sorted based on surface markers to enrich for CSC. Representative Western blot showing ER expression in sorted primary metastatic cells (A) and MCF7 cells (B). Anoikis resistant (AR) cells from primary metastatic and cell lines (MCF7 and T47D) were collected for protein and RNA. (C) Representative Western blot showing expression of ER in total versus AR cells, (D) mRNA expression level of ER (ESR1) and responsive genes in AR cells compared to total population. (E) Representative Western blot of ERK and phosphorylated (actived) ERK following culture for 48 hours in monolayer $\pm 1 \mathrm{nM} 17 \beta$-estradiol $\pm 1 \mu \mathrm{M}$ tamoxifen or gefitinib. (F) Mammosphere formation was assessed following culture with $1 \mathrm{nM} 17 \beta$-estradiol \pm gefitinib. Fold change is normalised to control, untreated cells represented as line. Means plotted $\pm \mathrm{SEM},{ }^{*} P<0.05,{ }^{* *} P<0.01,{ }^{* * *} P<0.001$ compared to E2 treated. \# $P<0.05$ compared to control cells. 
activation of the EGFR [6] and downstream phosphorylation of ERK [20]. We, therefore, measured activation of ERK signalling by ER and assessed the effect of the specific EGFR inhibitor gefitinib. Activation of ER signalling with $17 \beta$-estradiol caused increased phosphorylation of ERK which could be abrogated by treatment with tamoxifen or gefitinib, suggesting that ligand dependent ER signalling transactivates EGFR to phosphorylate ERK (Figure 3E). In mammosphere culture, gefitinib significantly reduced the effect of oestrogen in ER positive primary cells and lines (Figure 3F). However, with the exception of primary 3 , the MFC remained significantly higher compared to control cultures which were not exposed to oestrogen. These findings support the hypothesis that EGFR mediated paracrine signalling plays a role in the response to oestrogen but suggests other paracrine signals are also important.

\section{Notch signalling is involved in the oestrogenic effect on breast cancer stem cells}

Next, we investigated Notch signalling as another likely paracrine pathway since it has been reported [21] and we confirm here that Notch1 signalling activity increases following exposure to oestrogen (Figure 4A). Ligands of the Notch pathway are expressed at significantly lower levels in the CSC enriched sub-populations (Figure 4B) similar to the EGF ligand amphiregulin (Figure 3D) suggesting signalling may be initiated by ligands derived from the non-CSC sub-population. We predicted that Notch1 receptor signalling has a role in the oestrogenic response of breast CSCs and tested this using a gamma secretase inhibitor (GSI) known to specifically target Notch1 signalling [18]. GSI significantly reduced the oestrogenic effect on MFC in primary cells and MCF7 cells (Figure 4C) but the MFC number remained significantly increased compared to control MS cultures. However, GSI used in combination with gefitinib caused MFC number to fall below that seen in control conditions (Figure 4D). GSI had no effect on ERK phosphorylation, (Figure 4E) suggesting that the Notch and EGFR signalling pathways have distinct roles in the mediation of local signalling. We conclude from these data that both EGF and Notch1 receptor signalling are paracrine mediators of the effects of systemic oestrogen on breast CSC activity.

\section{Oestrogen stimulation increases tumour initiating cell number}

The effect of $17 \beta$-estradiol on CSC activity and frequency, and its inhibition using tamoxifen, gefitinib and GSI, was assessed with limiting dilution of cells injected into NSG mice. The human cell origin of xenografts was verified using human specific pan-cytokeratin staining (see Additional file 5, Figure S4). A total of 1,000 injected cells pre-treated with $17 \beta$-estradiol initiated tumours $\left(>100 \mathrm{~mm}^{3}\right.$ ) more quickly, and these tumours grew at a significantly faster rate than those formed from control cells or those treated with inhibitors $(P<$ 0.001 , Figure 5A).

Using L-Calc (Stem Cell Technologies, Grenoble, France), analysis of positive tumour growth (calculated as growth $\geq 100 \mathrm{~mm}^{3}$ ) across the limiting dilution series allowed estimation of the CSC number/tumour initiating cell frequency (TIF) within each treatment (Figure 5B). TIF increased from 1:475 in control cells to 1:22 in those treated with $17 \beta$-estradiol $(P=0.0019)$. Compared to $17 \beta$-estradiol treated cells those treated with tamoxifen, GSI or gefitinib + GSI showed significantly reduce TIF and levels in these cells were not significantly different to control. The effect of $17 \beta$-estradiol does not appear to be completely blocked by gefitinib and the TIF remains higher than in control cells although not significantly $(1: 107, P=0.118)$. This suggests that gefitinib alone is not able to completely block the effect of oestrogen but when used in combination with a Notch inhibitor it can increase efficiency.

\section{Discussion}

Our data show that breast CSC activity and cell surface marker expression is increased by oestrogen exposure. This effect is observed in all ER positive patient-derived primary cells and cell lines tested and can be demonstrated both in vitro, using mammosphere and holoclone culture, or in vivo, with limiting dilution analysis. We demonstrate that the CSC-enriched populations have low/no expression of ER suggesting that the effect seen is not a direct one and we establish EGF and Notch receptor signalling pathways as important paracrine mediators of oestrogen effects on CSC activity.

The data presented here are supportive of previously published work by Fillmore et al. [13] but contradicts other reports showing decreased CSC activity in the presence of oestrogen [14]. We hypothesise that this is due to differences in experimental design in these reports. Simões et al. [14] exposed cells in non-adherent mammosphere culture to oestrogen and, therefore, affected the CSC population during anoikis resistance and MS formation. In this paper, like Fillmore et al., we withdrew hormones and then incubated monolayer cultures of breast cancer cells with oestrogen before measurement of the CSC population changes. This suggests that in adherent culture oestrogen affects the proliferation and/or self-renewal of CSC whilst in non-adherent culture it may affect the survival or activity of CSC in a different way.

Previously published data show that sub-populations enriched for CSC have low expression of the oestrogen receptor $[13,22]$ but our data extend these findings to show decreased ER signalling within the CSC enriched population from metastatic ER positive patient samples. 


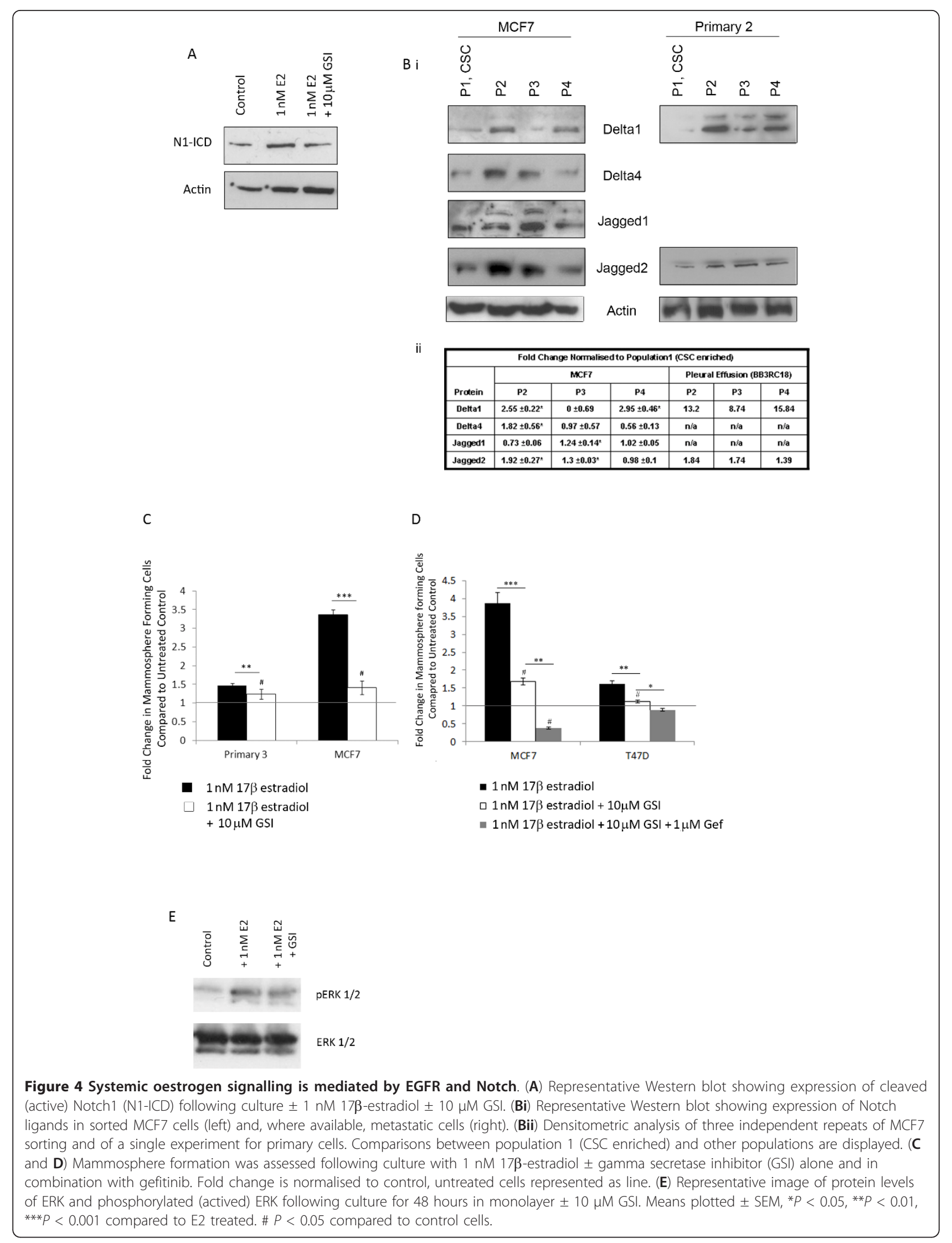




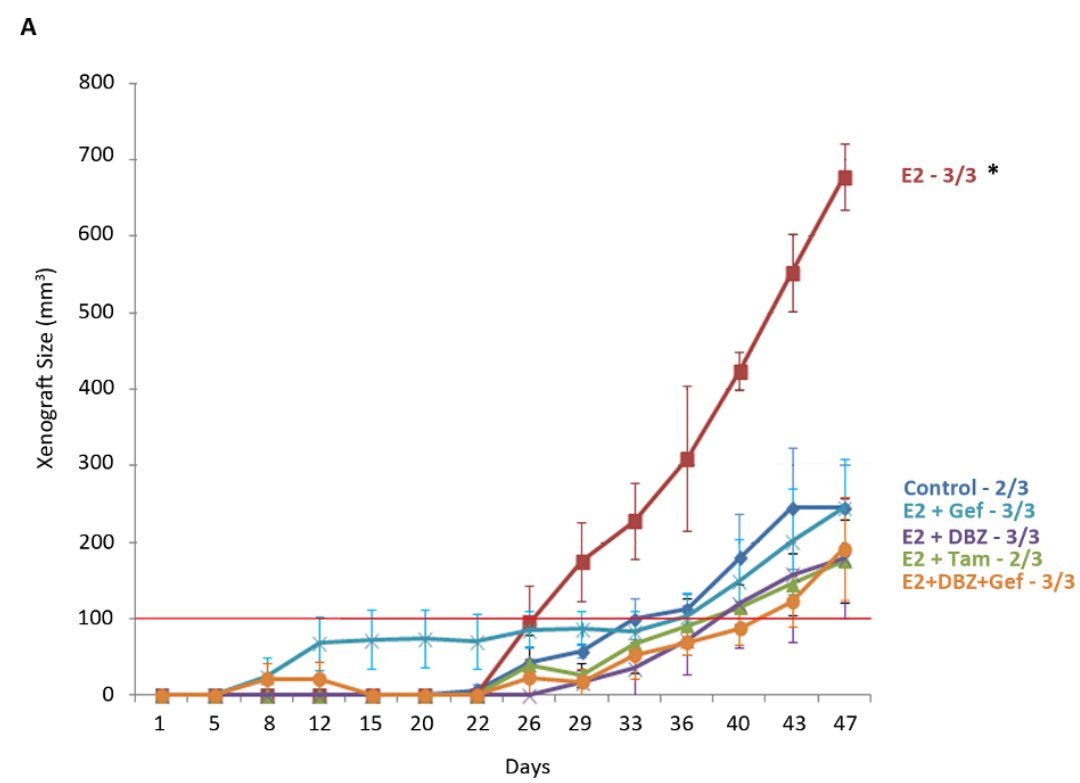

\begin{tabular}{|c|c|c|c|c|c|}
\hline Group & $\begin{array}{c}\text { Cell } \\
\text { Number }\end{array}$ & $\begin{array}{l}\text { Positive } \\
\text { Tumour } \\
\text { Growth }\end{array}$ & $\begin{array}{l}\text { Tumour In itiating Cell } \\
\text { Frequency }(95 \% \mathrm{Cl})\end{array}$ & $\begin{array}{c}P \text { from } \\
\text { Control } \\
\left(\chi^{2}\right)\end{array}$ & $\begin{array}{l}P \text { from E2 } \\
\left(\chi^{2}\right)\end{array}$ \\
\hline \multirow{3}{*}{ Control } & 1,000 & $2 / 3$ & \multirow{3}{*}{$1: 475(1: 137-1: 1,651)$} & \multirow{3}{*}{-} & \multirow{3}{*}{0.0009} \\
\hline & 100 & $2 / 3$ & & & \\
\hline & 10 & $0 / 3$ & & & \\
\hline \multirow{3}{*}{ E2 } & 1,000 & $3 / 3$ & \multirow{3}{*}{$1: 22(1.5-1.97)$} & \multirow{3}{*}{0.0009} & \multirow{3}{*}{-} \\
\hline & 100 & $3 / 3$ & & & \\
\hline & 10 & $1 / 3$ & & & \\
\hline \multirow{3}{*}{$\mathrm{E} 2+\mathrm{Tam}$} & 1,000 & $2 / 3$ & \multirow{3}{*}{$1: 362(1: 101-1: 1,301)$} & \multirow{3}{*}{0.7657} & \multirow{3}{*}{0.005} \\
\hline & 100 & $2 / 3$ & & & \\
\hline & 10 & $1 / 3$ & & & \\
\hline \multirow{3}{*}{$E 2+D B Z$} & 1,000 & $2 / 3$ & \multirow{3}{*}{$1: 486(1: 140-1: 1,696)$} & \multirow{3}{*}{0.97} & \multirow{3}{*}{0.0008} \\
\hline & 100 & $1 / 3$ & & & \\
\hline & 10 & $1 / 3$ & & & \\
\hline \multirow{3}{*}{$E 2+G$ ef } & 1,000 & $3 / 3$ & \multirow{3}{*}{$1: 108(1: 27-1: 432)$} & \multirow{3}{*}{0.114} & \multirow{3}{*}{0.114} \\
\hline & 100 & $2 / 3$ & & & \\
\hline & 10 & $0 / 3$ & & & \\
\hline \multirow{3}{*}{$\begin{array}{c}\mathrm{E} 2+\mathrm{DBZ}+ \\
\text { Gef }\end{array}$} & 1,000 & $3 / 3$ & \multirow{3}{*}{$1: 433(1: 124-1: 1,514)$} & \multirow{3}{*}{0.918} & \multirow{3}{*}{0.0041} \\
\hline & 100 & $0 / 3$ & & & \\
\hline & 10 & $0 / 3$ & & & \\
\hline
\end{tabular}

Figure 5 In vivo assessment of oestrogenic effect on breast cancer stem cells. (A) Growth curves for xenografts produced from 1,000 cells pre-treated $\pm 17 \beta$-estradiol, \pm inhibitors. ${ }^{*} P=0.01$ (B) In vivo tumour formation in each group represented as mice positive for growth/mice tested displayed for each cell number tested. Tumour initiating cell frequency $(95 \% \mathrm{Cl})$ estimates calculated from limiting dilution analysis.

The paracrine mediation of oestrogen signalling occurs in the normal breast through the EGFR pathway which activates ERK signalling and we demonstrate that this is also true in breast cancer. The inhibition of EGFR signalling does not, however, completely block the oestrogenic effects on CSC. An additive effect was seen when Notch inhibition with GSI was combined with gefitinib. This is supportive of recently published data which show an additive effect of EGFR/Notch inhibition on CSC activity in primary human ductal carcinoma in situ [23].

Notch1 was seen to increase as a result of oestrogen stimulation. In the normal breast, Notch1 is thought to play a role in the early luminal progenitor cells rather than stem cells and an analogous situation may, therefore, exist 
in cancers, whereby oestrogen exerts its effects on early differentiation progenitors of the CSC, rather than the CSC itself. This may suggest that early progenitor cells are directed to remain in a less differentiated state or that they de-differentiated into a more CSC-like cell type.
The data presented here are not directly in agreement with the previously published data showing FGF/Tbx3 signalling is responsible for this paracrine signalling in cancers [13]. There is, however, crosstalk between the two pathways and both are responsible for increased

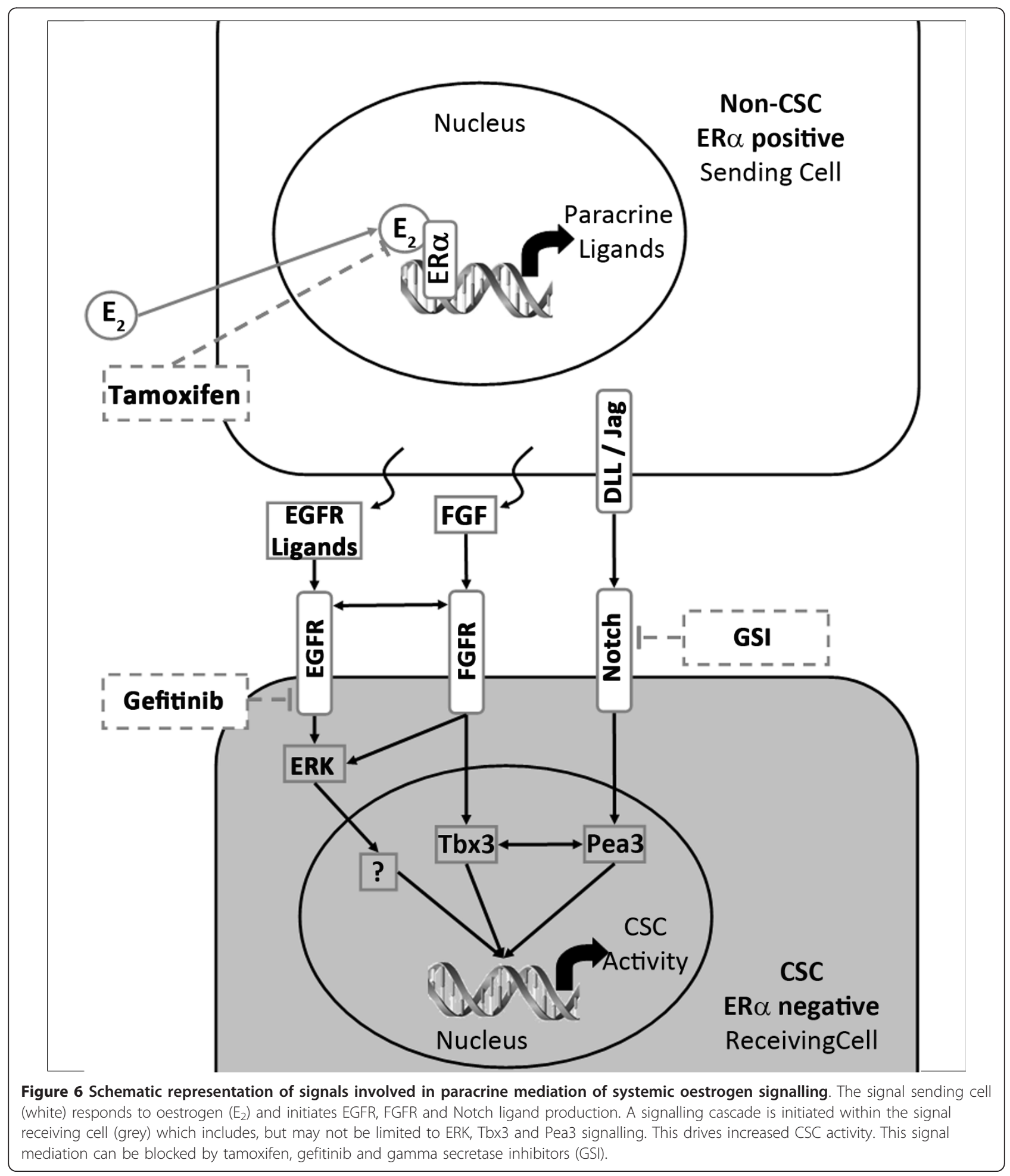


ERK signalling $[20,24]$. It is possible, therefore, that both pathways are involved in the oestrogenic response of the ER negative CSC/progenitor population. Furthermore, links between Tbx3 and Pea3 [25], a modulator of Notch signalling [26], support the crosstalk among EGF, FGF and Notch being responsible for CSC changes in response to oestrogen. A putative model for the paracrine signalling suggested by our results and the interactions identified by others is depicted in Figure 6.

\section{Conclusions}

In summary, our findings provide more evidence for the ER negative/low status of breast CSC in ER positive cell lines and patient derived samples. CSC number and activity increases in response to oestrogen stimulation and, as in the normal breast, this effect is partly mediated by EGFR signalling. We have further demonstrated that Notch signalling also plays a role in the stimulation of CSC expansion by oestrogen. The paracrine signals that mediate the oestrogenic effects on CSC suggest a role for EGFR and Notch signalling in endocrine resistance and may offer suitable targets for treatment of these tumours.

\section{Additional material}

Additional file 1: Table S1. Primary samples used in the study.

Additional file 2: Figure S1: Effect of $17 \beta$-oestradiol on cancer stem cell population. Mammosphere and holoclone formation and ESA ${ }^{+} C D 44$ ${ }^{+} \mathrm{CD} 24^{\text {low }}$ expression with varying concentrations of $17 \beta$-oestradiol.

Additional file 3: Figure S2: Gating protocol for cell analysis and sorting. Displays the gating procedure adopted.

Additional file 4: Figure S3: Analysis of primary cells following treatment with $17 \beta$-oestradiol. Displays FACS analysis of cells taken from patient derived sample following treatment with $17 \beta$-oestradiol.

Additional file 5: Figure S4: Xenograft characterization. Human origin of xenografts was confirmed using cytokeratin staining.

\section{Abbreviations}

ALDH1: aldehyde dehydrogenase; AR: anoikis resistant; AREG: amphiregulin; BSA: bovine serum albumin; CSC: cancer stem cell; DMEM: Dulbecco's modified Eagle's medium; EGF: epidermal growth factor; EGFR: epidermal growth factor receptor; ER: oestrogen receptor alpha; ESA: epithelial specific antigen; FGF: fibroblast growth factor; GSI: gamma secretase inhibitors; HBSS: Hank's buffered saline solution; HFC: holoclone forming cell; MFC: mammosphere forming cell; MS: mammosphere; MSC: mammary stem cell; N1-ICD: Notch1 intracellular domain; NSG mice: NOD SCID IL2gammaR knock-out mice; PBS: phosphate-buffered solution; Tam: tamoxifen; TIF: tumour initiating cell frequency

\footnotetext{
Authors' contributions

$\mathrm{HH}$ was involved in study design, carried out the majority of the practical experimentation and drafted the manuscript. BMS managed in vivo experimentation and assisted in manuscript preparation. LR assisted in siRNA and Western blotting experiments. SJH identified and collected samples, provided clinical details and assisted with manuscript preparation. GL provided assistance with experimental design and manuscript preparation. RBC conceived of the study and participated in the experimental design and
}

manuscript production. All authors have read and approved the final version of this manuscript.

\section{Competing interests}

The authors declare that they have no competing interests.

\section{Acknowledgements}

Thanks to the patients who contributed samples to this research. $\mathrm{HH}$ was funded by EU project and Breakthrough Breast Cancer. RBC was funded by Breast Cancer Campaign. LR and GL were funded by Breakthrough Breast Cancer.

\section{Author details}

${ }^{1}$ Molecular Pathology Group, Breakthrough Breast Cancer Research Unit, Institute of Cancer Sciences, University of Manchester, Paterson Institute for Cancer Research, Manchester, M20 4BX, UK. ㄹ Breast Biology Group, Institute of Cancer Sciences, University of Manchester, Paterson Institute for Cancer Research, Manchester, M20 4BX, UK. ${ }^{3}$ Department of Medical Oncology, The University of Manchester, The Christie NHS Foundation Trust, Manchester, M20 4BX, UK. “Sahlgrenska Cancer Center, Institute of Biomedicine, 40530 Göteborg, Sweden.

Received: 19 March 2012 Revised: 6 February 2013

Accepted: 5 March 2013 Published: 8 March 2013

\section{References}

1. Stingl J, Eirew P, Ricketson I, Shackleton M, Vaillant F, Choi D, Li HI, Eaves CJ: Purification and unique properties of mammary epithelial stem cells. Nature 2006, 439:993-997.

2. Woodward WA, Chen MS, Behbod F, Rosen JM: On mammary stem cells. J Cell Sci 2005, 118:3585-3594.

3. Bocchinfuso WP, Korach KS: Mammary gland development and tumorigenesis in estrogen receptor knockout mice. J Mammary Gland Biol Neoplasia 1997, 2:323-334.

4. Shackleton M, Vaillant F, Simpson KJ, Stingl J, Smyth GK, Asselin-Labat ML, Wu L, Lindeman GJ, Visvader JE: Generation of a functional mammary gland from a single stem cell. Nature 2006, 439:84-88.

5. Sleeman KE, Kendrick H, Ashworth A, Isacke CM, Smalley MJ: CD24 staining of mouse mammary gland cells defines luminal epithelial, myoepithelial/ basal and non-epithelial cells. Breast Cancer Res 2006, 8:R7.

6. Ciarloni L, Mallepell S, Brisken C: Amphiregulin is an essential mediator of estrogen receptor alpha function in mammary gland development. Proc Natl Acad Sci USA 2007, 104:5455-5460.

7. Al-Hajj M, Wicha MS, Benito-Hernandez A, Morrison SJ, Clarke MF: Prospective identification of tumorigenic breast cancer cells. Proc Natl Acad Sci USA 2003, 100:3983-3988.

8. Ginestier $\mathrm{C}$, Hur MH, Charafe-Jauffret E, Monville F, Dutcher J, Brown M, Jacquemier J, Viens P, Kleer CG, Liu S, Schott A, Hayes D, Birnbaum D, Wicha MS, Dontu G: ALDH1 is a marker of normal and malignant human mammary stem cells and a predictor of poor clinical outcome. Cell Stem Cell 2007, 1:555-567.

9. Stylianou S, Clarke RB, Brennan K: Aberrant activation of notch signaling in human breast cancer. Cancer Res 2006, 66:1517-1525.

10. Phillips TM, McBride WH, Pajonk F: The response of CD24(-/low)/CD44+ breast cancer-initiating cells to radiation. J Natl Cancer Inst 2006, 98:1777-1785.

11. Haughian JM, Pinto MP, Harrell JC, Bliesner BS, Joensuu KM, Dye WW Sartorius CA, Tan AC, Heikkila P, Perou CM, Horwitz KB: Maintenance of hormone responsiveness in luminal breast cancers by suppression of Notch. Proc Natl Acad Sci USA 2012, 109:2742-2747.

12. Rizzo P, Miao H, D'Souza G, Osipo C, Yun J, Zhao H, Mascarenhas J, Wyatt D, Antico G, Hao L, Yao K, Rajan P, Hicks C, Siziopikou K, Selvaggi S, Bashir A, Bhandari D, Marchese A, Lendahl U, Qin JZ, Tonetti DA, Albain K, Nickoloff BJ, Miele L: Cross-talk between notch and the estrogen receptor in breast cancer suggests novel therapeutic approaches. Cancer Res 2008, 68:5226-5235.

13. Fillmore CM, Gupta PB, Rudnick JA, Caballero S, Keller PJ, Lander ES, Kuperwasser C: Estrogen expands breast cancer stem-like cells through paracrine FGF/Tbx3 signaling. Proc Natl Acad Sci USA 2010, 107:21737-21742. 
14. Simoes BM, Piva M, Iriondo O, Comaills V, Lopez-Ruiz JA, Zabalza I, Mieza JA, Acinas O, Vivanco MD: Effects of estrogen on the proportion of stem cells in the breast. Breast Cancer Res Treat 2011, 129:23-35.

15. Grenman R, Burk D, Virolainen E, Buick RN, Church J, Schwartz DR, Carey TE: Clonogenic cell assay for anchorage-dependent squamous carcinoma cell lines using limiting dilution. Int I Cancer 1989, 44:131-136.

16. ImageJ: Image Processing and Analysis in Java. [http://rsb.info.nih.gov/ij].

17. StemCell ${ }^{\mathrm{TM}}$ Technologies. [http://www.stemcell.com/en/Products/AllProducts/LCalc-Software.aspx].

18. Harrison H, Farnie G, Howell SJ, Rock RE, Stylianou S, Brennan KR, Bundred NJ, Clarke RB: Regulation of breast cancer stem cell activity by signaling through the Notch4 receptor. Cancer Res 2010, 70:709-718.

19. Harrison H, Rogerson L, Gregson HJ, Brennan KR, Clarke RB, Landberg G: Contrasting hypoxic effects on breast cancer stem cell hierarchy is dependent on ERalpha status. Cancer Res 2013, 73:1420-1433.

20. Gilmore JL, Scott JA, Bouizar Z, Robling A, Pitfield SE, Riese DJ, Foley J: Amphiregulin-EGFR signaling regulates PTHrP gene expression in breast cancer cells. Breast Cancer Res Treat 2008, 110:493-505.

21. Soares R, Balogh G, Guo S, Gartner F, Russo J, Schmitt F: Evidence for the notch signaling pathway on the role of estrogen in angiogenesis. Mol Endocrinol 2004, 18:2333-2343.

22. Shipitsin M, Campbell LL, Argani P, Weremowicz S, Bloushtain-Qimron N, Yao J, Nikolskaya T, Serebryiskaya T, Beroukhim R, Hu M, Halushka MK, Sukumar S, Parker LM, Anderson KS, Harris LN, Garber JE, Richardson AL, Schnitt SJ, Nikolsky Y, Gelman RS, Polyak K: Molecular definition of breast tumor heterogeneity. Cancer Cell 2007, 11:259-273.

23. Farnie G, Willan PM, Clarke RB, Bundred NJ: Combined inhibition of ErbB1/ 2 and Notch receptors effectively targets breast ductal carcinoma in situ (DCIS) stem/progenitor cell activity regardless of ErbB2 status. PLoS One 2013, 8:e56840.

24. Ding W, Shi W, Bellusci S, Groffen J, Heisterkamp N, Minoo P, Warburton D: Sprouty2 downregulation plays a pivotal role in mediating crosstalk between TGF-beta1 signaling and EGF as well as FGF receptor tyrosine kinase-ERK pathways in mesenchymal cells. I Cell Physiol 2007, 212:796-806

25. Mesbah K, Harrelson Z, Theveniau-Ruissy M, Papaioannou VE, Kelly RG: Tbx3 is required for outflow tract development. Circ Res 2008, 103:743-750.

26. Clementz AG, Rogowski A, Pandya K, Miele L, Osipo C: NOTCH-1 and $\mathrm{NOTCH}-4$ are novel gene targets of PEA3 in breast cancer: novel therapeutic implications. Breast Cancer Res 2011, 13:R63.

doi:10.1186/bcr3396

Cite this article as: Harrison et al:: Oestrogen increases the activity of oestrogen receptor negative breast cancer stem cells through paracrine EGFR and Notch signalling. Breast Cancer Research 2013 15:R21.

\section{Submit your next manuscript to BioMed Central and take full advantage of:}

- Convenient online submission

- Thorough peer review

- No space constraints or color figure charges

- Immediate publication on acceptance

- Inclusion in PubMed, CAS, Scopus and Google Scholar

- Research which is freely available for redistribution

Submit your manuscript at www.biomedcentral.com/submit
Biomed Central 